\title{
Associations between physical activity, sedentary behaviour and self-rated health among the general population of children and adolescents: a systematic review and meta-analysis
}

\author{
Tong Zhang, Guohua Lu and Xiu Yun Wu ${ }^{*}$
}

\begin{abstract}
Background: Self-rated health (SRH) is an indicator that captures a person's perception of their overall health status. The relationship between physical activity (PA), sedentary behaviour (SB) and SRH has been investigated in systematic reviews among adult and elderly populations. No systematic review to date has synthesized the relationship between PA, SB and SRH among children and adolescents. The purpose of this systematic review and meta-analysis was to synthesize the associations between PA, SB and SRH in the general population of children and adolescents and to investigate the dose-response relationship between PA, SB and SRH.

Methods: We conducted a computer search for English language studies in the databases of MEDLINE, EMBASE and PSYCINFO that were published between 1946 and 2019. We searched PubMed, Google Scholar, and the references of the identified publications for additional studies. A meta-analysis was employed to synthesize the associations between PA, SB respectively and SRH. The dose-response association was tested using a random effects meta-regression model. The review was reported following the Preferred Reporting Items for Systematic reviews and Meta-Analyses (PRISMA) guidelines.

Results: Sixty-eight published articles were included in the final review, including 59 cross-sectional and nine longitudinal studies. We found evidence that PA was associated with better SRH, and SB was associated with lower SRH among children and adolescents. A dose-response relationship between PA and SRH was observed, where a higher level of PA was associated with better SRH than a lower level of PA. The relationship between PA, SB and SRH was observed in both boys and girls, and did not show a significant gender difference.

Conclusions: The findings in the systematic review suggest that health intervention programmes targeting promoting PA and reducing SB among children and adolescents may enhance their overall health status. Future research is needed to expand prospective cohort and intervention studies to address directionality and causality in the relationships between PA, SB and SRH among children and youth.

(Continued on next page)
\end{abstract}

\footnotetext{
*Correspondence: xiuyunwu777@yahoo.com

School of Public Health, Weifang Medical University, 7166 Baotong West

Street, Weifang 261053, Shandong, China
}

(c) The Author(s). 2020 Open Access This article is licensed under a Creative Commons Attribution 4.0 International License, which permits use, sharing, adaptation, distribution and reproduction in any medium or format, as long as you give appropriate credit to the original author(s) and the source, provide a link to the Creative Commons licence, and indicate if changes were made. The images or other third party material in this article are included in the article's Creative Commons licence, unless indicated otherwise in a credit line to the material. If material is not included in the article's Creative Commons licence and your intended use is not permitted by statutory regulation or exceeds the permitted use, you will need to obtain permission directly from the copyright holder. To view a copy of this licence, visit http://creativecommons.org/licenses/by/4.0/ The Creative Commons Public Domain Dedication waiver (http://creativecommons.org/publicdomain/zero/1.0/) applies to the data made available in this article, unless otherwise stated in a credit line to the data. 
(Continued from previous page)

Trial registration: PROSPERO - CRD42019142244. Registered on October 18, 2019.

Keywords: Children, Adolescents, Physical activity, Sedentary behaviour, Self-rated health, Systematic review, Metaanalysis

\section{Background}

Self-rated health (SRH) or self-perceived health captures a person's perception of their overall health status, physical health and mental health and has been used as an indicator of health-related quality of life (HRQOL) $[1,2]$. It is commonly measured by a single-item question with a 5or 4-point Likert response scale indicating a graded level of health status (e.g., from "poor" to "excellent" health). SRH covers multiple aspects of health status, including general physical functioning, psychological health and health behaviours. Previous studies have shown that SRH is associated with a wide range of physical and mental health concerns and is an independent predictor of morbidity and mortality [3-7]. Prior research has also documented that SRH is a stable health outcome measure from adolescence to early adulthood [2, 7]. The use of self-perceived health as a global health indicator can provide insights into the effect of behavioural risk factors on overall health among children and youth. Assessment of child and youth's self-perceived health is important to identify children and adolescents with poor health and to guide population health intervention programmes targeted improving children and youth's health.

The health benefits of physical activity (PA) have been well established among adult populations $[8,9]$. Among children and adolescents, it has been documented that PA is associated with both physical and mental health and HRQOL [10-14]. Promoting PA among children and adolescents is beneficial for childhood and adolescent obesity prevention as well as some chronic disease conditions (e.g., cardiovascular disease, depression) [10, $12,15]$. Sedentary behaviour (SB) is defined as "any waking behaviour characterized by an energy expenditure $\leq 1.5$ metabolic equivalents (METs), while in a sitting or reclining posture" [16]. SB is associated with an adverse health status in children and adolescents. The impaired health consequences from SB include but are not limited to physical disabilities, poor psychological health and mental health disorders (e.g., depression, anxiety) among children and adolescents [10, 1720]. Over the last two decades, the rapid development of science and technology has led to the popular use of electronic media devices among adults, youth and children. Children and adolescents increasingly engage in watching television (TV), excessive use of smartphones, playing video games or computer games, resulting in excessive sedentary time and decreased time in physical and sports activities [17]. Therefore, it is important to study the impact of PA and SB on health among children and adolescents.

The relationship between PA, SB and self-rated health has been mostly investigated among adult and elderly populations, and the relationship of PA, SB with SRH is shown in a dose-response pattern [21-24]. In children and adolescents, the association between PA, SB and multidimensional HRQOL has been investigated [13]. Our previous systematic review study showed that an inactive lifestyle and higher sedentary time correlated with lower HRQOL, including overall HRQOL and the physical and mental components of HRQOL among children and adolescents [13]. Studies on the associations among PA, SB and SRH in children and adolescents have emerged during the last decade [1, 25-28]. However, to the best of our knowledge, no systematic review has comprehensively investigated the relationships between $\mathrm{PA}, \mathrm{SB}$ and $\mathrm{SRH}$ among children and youth. Specifically, there is a lack of evidence concerning the nature of the relationship of PA, SB with SRH in terms of strength, dose-response and linearity. A systematic review in this field will help to provide a better understanding of the associations of SRH with health-related behaviours and is important to provide evidence-based recommendations for guiding population health programmes aimed at promoting active living and healthy lifestyles among children and adolescents.

The purpose of this systematic review was to synthesize associations between PA, SB and SRH in the general population of children and adolescents and to investigate the dose-response relationship between PA, SB and SRH.

\section{Methods}

\section{Protocol and registration}

This systematic review was registered with the International Prospective Register of Systematic Reviews (PROSPERO; Registration number: CRD42019142244), available from https://www.crd.york.ac.uk/prospero/display_record.

php?RecordID $=142244$. We reported this review following the Preferred Reporting Items for Systematic reviews and Meta-Analyses (PRISMA) guidelines [29].

\section{Literature search}

We conducted searches in the MEDLINE, PSYCINFO and EMBASE electronic databases for English literature 
published from 1946 to December 30, 2019. The database searches were initiated in October and November 2018, and the update search was conducted in February 2020. The medical subject headings and keywords used in the electronic database search included 'physical activity', 'exercise', 'accelerometer', 'sedentary behaviour', 'screen time', 'television, or TV, or television viewing', 'computers', 'video games', 'lifestyle', 'quality of life', 'health status', 'self-rated health', 'self-perceived health', 'self-report health', 'children', 'adolescents', 'childhood', 'adolescence', and 'youth'. The detailed literature search strategy for the electronic databases and the number of retrieved records are provided in the Additional files (see Additional file 1). We searched PubMed and manually checked the references in the identified included studies and the relevant reviews and meta-analyses for additional eligible studies. We also executed Google Scholar searches to identify additional published articles and unpublished studies. The database searches were conducted by one author.

\section{Inclusion and exclusion criteria}

The following inclusion criteria were adopted for selection of the eligible studies: (1) Studies used a single-item question representing self-rated or self-perceived health as the primary outcome. The response options were in the form of a Likert scale (from "poor" to "excellent" health). Self-rated health was defined as health reported by children or adolescents themselves or by parents for their children's health when the children were less than 8 years old. (2) Study participants were drawn from schools or communities representing the general population of children and adolescents aged primarily between 3 years and 19 years. For longitudinal studies with a follow-up age greater than 19 years, the age range was applied to the baseline time point when the exposure measure was collected. (3) The study design included cross-sectional, cohort and case-control studies that examined the association between PA and/or SB and SRH. (4) Measures of the exposure included physical activity and sedentary behaviour. Both subjective and objective measures were included.

The exclusion criteria included (1) studies that examined associations between PA, SB and SRH among children and adolescents with specific chronic disease conditions (e.g., obesity or diabetes) or among adults; (2) publications that were reviews, meta-analyses, study protocols, conference abstracts and proceedings, non-peerreviewed journal articles, comments, letters, case reports and guidelines.

The relevant reviews and meta-analyses were not included in the synthesis, but their reference lists were examined for identification of other eligible studies that were not found in the database search. As the literature search for unpublished studies identified no other unpublished studies except one thesis that met the inclusion criteria [30], we excluded the thesis in the review.

\section{Study selection}

The retrieved citations from the database search were independently screened by two authors, XYW and TZH for selection of the studies. The authors screened the titles and abstracts of the references in accordance with the predefined inclusion and exclusion criteria. For potential qualified studies, the full-text articles were retrieved and then separately reviewed by the two authors to determine the eligibility for inclusion. The full-text articles of relevant reviews and meta-analyses were also retrieved for examination of the references. Disagreements regarding the eligibility of the studies for inclusion were resolved by discussion among all the authors.

\section{Data extraction}

We used a standardized extraction form to collect data from individual studies for the synthesis. The extracted information included characteristics of the study (e.g., first author, country, publication year, study design, sample size, participants' age and gender), assessments of the exposure and outcomes, statistical methods, main findings and risk of bias assessment for each study. The data for meta-analysis were extracted using a Microsoft Excel spreadsheet.

\section{Data synthesis}

The extracted data from individual studies were narratively synthesized in summary tables, including the characteristics and key findings of each study. The statistics for the associations among PA, SB and SRH within a study included an odds ratio (OR) and the 95\% confidence interval (CI) in a logistic regression or a regression coefficient and the $95 \% \mathrm{CI}$ in a linear regression.

For those studies with quantitative data suitable for meta-analysis, we performed a meta-analysis to synthesize the overall associations between the exposure of interest and SRH. As most included studies utilised a logistic regression using a binary categorical SRH outcome (e.g., "poor" versus "good" health), we estimated the difference in the odds of poor SRH between a lower level and a higher level of PA. For the effect of SB, we estimated the difference in the odds of poor SRH between a higher level of SB (e.g., $\geq 2 \mathrm{~h} /$ day) and a lower level of SB (e.g., < $2 \mathrm{~h} /$ day). Subgroup meta-analyses were conducted by gender of the participants, PA dose level and type of SBs (TV viewing, use of computers and total screen time). To account for potential heterogeneity across studies, we used a random effects model in the meta-analysis. The Cochran $\mathrm{Q}$ and $\mathrm{I}^{2}$ statistics were used to test the degree of heterogeneity. A $p$-value less than 
0.1 in the $\mathrm{Q}$ test and an $\mathrm{I}^{2}$ value greater than $50 \%$ indicated statistically significant and substantial heterogeneity, respectively [31]. To test the statistical significance of the dose-response relationship between PA and health status, we used a meta-regression, where the effects of both within- and between-study variances were accounted for. Publication bias was detected using a funnel plot and Egger's test [32, 33]. The funnel plot asymmetry was tested by Egger's test, in which the standardized effect (e.g., log odds) was regressed against its standard error (precision), with a $p$-value $<0.1$ for the intercept $(\alpha)$ indicating a statistically significant asymmetry or a presence of publication bias [33]. The metaanalysis was conducted using Stata/SE 15.0 (Stators LLC, College Station, Texas, USA).

\section{Assessment of risk of bias}

We used the Quality Assessment Tool for Observational Cohort and Cross-Sectional Studies (QATOCCS) provided by the US National Heart, Lung, and Blood Institute [34] to evaluate the risk of bias. The QATOCCS included 14 questions covering the following aspects: research question and study objective, population specification, participation rate, recruitment of participants, sample size justification, time of the exposure collection, time of study, exposure levels, validation of exposure assessment, outcome measures and blinding, loss to follow-up, and adjustment of potential confounding variables in regression analyses. Each question was assigned a score of one if a confirmative answer 'yes' was appropriate for the study. The total score was obtained by sum of the score for each question, ranging between zero and 14, with a higher total score for a study indicating low risk of bias. In reference to the previous research for categorization of the study quality level [17], a study was classified as high quality or low risk of bias (score 11-12), medium quality or moderate risk of bias (score 9-10), and low quality or potential high risk of bias (score 7-8).

\section{Results}

\section{Characteristics of the included studies}

We identified 22,234 citations through the electronic database search in MEDLINE $(n=11,552)$, EMBASE $(n=9849)$ and PSYCINFO $(n=833)$. An additional 12 articles were obtained through the reference list, PubMed and Google Scholar searches for related articles. After deleting duplicate records identified in the different databases $(n=2980)$, we screened 19,266 published records for eligibility through title and abstract review. Of these, 150 studies were retained for full-text evaluation, and 82 of them were then excluded due to ineligibility. Finally, 68 studies met the inclusion criteria and were included in the synthesis (Table 1 ). The study selection is presented in the PRISMA flow diagram (Fig. 1). The excluded references in the full text evaluation are presented in the Additional files (see Additional file 2).

Table 1 presents the major characteristics of the included studies, the findings of the associations and the risk of bias assessment. The detailed results are presented in the Additional files, including the assessments of PA, SB and SRH, statistical methods and confounders adjusted for in the regression, and the key results (see Additional file 3). The review included 59 crosssectional studies and nine longitudinal studies [1-4, 25$28,35-94]$. Most of the studies $(n=43)$ were conducted in European countries (e.g., UK, Spain, Finland, Sweden, Norway, Portugal, Hungary) or used data from multiple countries. The remaining 25 studies came from other countries, including the United States $(n=5)$, Canada $(n=4)$, Australia $(n=3)$, Japan $(n=3)$, Brazil $(n=3)$, Peru $(n=2)$, South Korea $(n=2)$, Iran $(n=1)$, Pakistan $(n=1)$ and Thailand $(n=1)$. The sample size of the studies varied between 245 (the smallest sample study) [65] and 136,589 (the largest sample study) [59]. Of the included studies, 24 studies examined both PA and SB for health status, 38 studies assessed the association between PA and SRH, and six studies analysed the effect of SB on SRH.

Most of the studies used self-report questionnaires to evaluate PA and SB. PA was measured by asking children or adolescents about their physical activities (type and intensity, duration and frequency) within the past 7 days or one month. SB was usually measured by time (hours or minutes) spent on sedentary behaviours (e.g., watching TV, playing video games, using computers, etc.) in a week or a day. Two studies used a devicemeasure of PA and SB (e.g., accelerometer) [3, 25]. Selfrated health was mostly categorized into two groups ("poor" versus "good" health) and analysed with logistic regression. Six studies used ordinal logistic or multinomial logistic regression models [2, 28, 73, 74, 86, 93]. Six studies used a linear regression treating SRH as a continuous variable $[53,63,67,81,89,91]$.

\section{Risk of bias assessment}

Fifteen studies were rated as high quality or low risk of bias (score range 11-12), 39 studies were rated as medium quality or moderate risk of bias (score range 910), and 14 studies were classified as low quality or high risk of bias (score 7-8) (Table 1). The reasons for categorizing studies with a high risk of bias included a small sample or convenience sample, inadequate statistical analysis (e.g., not adjusting for confounding effects in regression analysis), or use of limited exposure levels of PA. 
Table 1 Sample characteristics and the key finding for the association between PA, SB and SRH of the included studies ( $N=68$ )

\begin{tabular}{|c|c|c|c|c|c|}
\hline \multirow[t]{2}{*}{ First author, publication year and country } & \multirow[t]{2}{*}{ Sample $\boldsymbol{n}$ (\% of girl) } & \multirow{2}{*}{$\begin{array}{l}\text { Mean age (years) or } \\
\text { age range }\end{array}$} & \multicolumn{2}{|c|}{ Associations } & \multirow{2}{*}{$\begin{array}{l}\text { Risk } \\
\text { of } \\
\text { bias } \\
\text { score }\end{array}$} \\
\hline & & & $\begin{array}{l}\mathrm{PA} \text { and } \\
\mathrm{SRH}\end{array}$ & SB and SRH & \\
\hline \multicolumn{6}{|l|}{ Cross-sectional study } \\
\hline Marques, 2019 Portugal [35] & $5024(52.8)$ & 13.9 & $\mathrm{P}+$ & NS & 9 \\
\hline Silva, 2019 Brazil [36] & $6259(59.7)$ & 16.6 & $P+$ & - & 9 \\
\hline Jodkowska, 2019 Poland [37] & 1173 (Girls only) & 15 & $\mathrm{P}+$ & N- & 8 \\
\hline Werneck, 2018 Brazil [38] & $984(58.8)$ & $10-17$ & - & N- & 9 \\
\hline Li, 2018 Japan [39] & $4966(50.7)$ & 15.8 & $\mathrm{P}+$ & $\mathrm{N}$ - for girls & 9 \\
\hline Granger, 2017 European countries [40] & 13,783 & 15 & $\mathrm{P}+$ & NS & 10 \\
\hline Lachytova, 2017 Slovak Republic [4] & 1111 & $14-16$ & $\mathrm{P}+$ & N- & 10 \\
\hline Matin, 2017 Iran [41] & $13,486(49.2)$ & 12.47 & $\mathrm{P}+$ & N- & 10 \\
\hline Novak, 2017 Croatia, Lithuania and Serbia [27] & $6501(52)$ & $14-19$ & $\mathrm{P}+$ & - & 10 \\
\hline Sharma, 2017 Peru [26] & $1234(61.4)$ & $11-19$ & $\mathrm{P}+$ & - & 10 \\
\hline Husu, 2016 Finland [25] & 851 & $7-14$ & $\mathrm{P}+$ & N- & 12 \\
\hline Koelmeyer, 2016 Australia [42] & 2717 (Males only) & $10-19$ & $P+$ & - & 7 \\
\hline Sharma, 2016 Peru [43] & $970(53.8)$ & 14.5 & $\mathrm{P}+$ & N- & 10 \\
\hline Ustinavičienè, 2016 Lithuania [44] & $1730(49.8)$ & $\begin{array}{l}15.86 \text { (boys), } \\
15.81 \text { (girls) }\end{array}$ & - & $\mathrm{N}$ - for boys & 8 \\
\hline Badura, 2015 Czech Republic [45] & $10,503(50.8)$ & $11,13,15$ & $\mathrm{P}+$ & - & 9 \\
\hline Herman, 2015 Canada [1] & $7725(49)$ & $12-17$ & $\mathrm{P}+$ & N- & 11 \\
\hline Kantomaa, 2015 Finland [46] & 7063 & 16 & $P+$ & - & 10 \\
\hline Martínez-López, 2015 Spain [47] & $2293(50.2)$ & 14.2 & $\mathrm{P}+$ & N- & 11 \\
\hline Meireles, 2015 Brazil [48] & $1042(47.2)$ & $11-17$ & $P+$ & NS & 9 \\
\hline Padilla-Moledo, 2015 Spain [49] & $680(46.0)$ & $6-17.9$ & - & N- & 9 \\
\hline Novak, 2015 Croatia [50] & $3427(50.7)$ & $17-18$ & $\mathrm{P}+$ & - & 9 \\
\hline Smith, 2015 UK [51] & 3105 & $11-12$ & NS & NS & 9 \\
\hline Chun, 2014 South Korea [52] & 3676 & $16-18$ & $\mathrm{P}+$ & - & 9 \\
\hline Craike, 2014 Australia [53] & 732 (Girls only) & $7-11$ & NS & - & 8 \\
\hline Dyremyhr, 2014 Norway [54] & 2510 & $15-20$ & $\mathrm{P}+$ & - & 9 \\
\hline Herman, 2014 Canada [3] & $527(46.3)$ & $\begin{array}{l}9.64 \text { (boys), } 9.59 \\
\text { (girls) }\end{array}$ & $\begin{array}{l}\text { P+ for } \\
\text { boys }\end{array}$ & $\begin{array}{l}\mathrm{N} \text { - for girls (PC/ } \\
\text { video) }\end{array}$ & 11 \\
\hline Kovacs, 2014 Hungary [55] & $881(44.6)$ & 16.6 & $\mathrm{P}+$ & - & 8 \\
\hline $\begin{array}{l}\text { Moor, } 201428 \text { European and North American } \\
\text { countries [56] }\end{array}$ & $117,460(53.3)$ & $11-15$ & $\mathrm{P}+$ & N- & 10 \\
\hline Brooks, 2014 UK [57] & $4404(51.6)$ & $11,13,15$ & $\mathrm{P}+$ & - & 8 \\
\hline Afridi, 2013 Pakistan [58] & $414(46.1)$ & 14.36 & NS & - & 9 \\
\hline Do, 2013 South Korea [59] & $136,589(47.7)$ & $13-18$ & - & N- & 11 \\
\hline Galán, 2013 Spain [60] & 21,188 & $11-18$ & $\mathrm{P}+$ & - & 11 \\
\hline Spein, 2013 Greenland and Norway [61] & $728(56.5)$ & $15-16$ & $\mathrm{P}+$ & - & 8 \\
\hline Richter, 2012 Germany [62] & $6997(49.9)$ & $11-15$ & $\mathrm{P}+$ & - & 10 \\
\hline Tabak, 2012 Poland [63] & $600(50.8)$ & $13.2-13.7$ & $\mathrm{P}+$ & NS & 7 \\
\hline Veloso, 2012 Portugal [64] & $3069(54.1)$ & 14.8 & $\mathrm{P}+$ & N- & 9 \\
\hline Zullig, 2011 US [65] & $245(54.7)$ & $11-15$ & $\mathrm{P}+$ & NS & 7 \\
\hline Foti, 2010 US [66] & 12,193 & $\begin{array}{l}\text { grade 9-12 high } \\
\text { school }\end{array}$ & $\mathrm{P}+$ & N- & 10 \\
\hline Iannotti, 2009 North America and Europe [67] & 49,124 & $11,13,15$ & $\mathrm{P}+$ & N- & 11 \\
\hline
\end{tabular}


Table 1 Sample characteristics and the key finding for the association between PA, SB and SRH of the included studies ( $N=68$ ) (Continued)

\begin{tabular}{|c|c|c|c|c|c|}
\hline \multirow[t]{2}{*}{ First author, publication year and country } & \multirow[t]{2}{*}{ Sample $\boldsymbol{n}$ (\% of girl) } & \multirow{2}{*}{$\begin{array}{l}\text { Mean age (years) or } \\
\text { age range }\end{array}$} & \multicolumn{2}{|c|}{ Associations } & \multirow{2}{*}{$\begin{array}{l}\text { Risk } \\
\text { of } \\
\text { bias } \\
\text { score }\end{array}$} \\
\hline & & & $\begin{array}{l}\text { PA and } \\
\text { SRH }\end{array}$ & SB and SRH & \\
\hline Kahlin, 2009 Sweden [68] & $1090(57.1)$ & 18.1 & $\mathrm{P}+$ & - & 10 \\
\hline Mathers, 2009 Australia [69] & $925(49.6)$ & 16.1 & - & $\mathrm{N}$ - for video games & 9 \\
\hline Page, 2009a Thailand [70] & $2492(66.7)$ & 16.2 & $\mathrm{P}+$ & - & 7 \\
\hline Page, 2009b Central and Eastern European [71] & 3123 & 16.6 & $\mathrm{P}+$ & - & 9 \\
\hline $\begin{array}{l}\text { Richter, } 2009 \text { European and North American countries } \\
\text { [72] }\end{array}$ & $97,721(52.0)$ & 13,15 & $\mathrm{P}+$ & N- & 10 \\
\hline Breidablik, 2008 Norway [73] & 2741 & 18.3 & $\mathrm{P}+$ & - & 11 \\
\hline Söderqvist, 2008 Sweden [74] & $1269(52.2)$ & $15-19$ & - & N- & 11 \\
\hline Kelleher, 2007 Ireland, Europe and North America [75] & $123,653(51.1)$ & $9-18$ & $\mathrm{P}+$ & N- & 8 \\
\hline Piko, 2007a Hungary [76] & $1114(60.1)$ & 16.5 & $\mathrm{P}+$ & - & 10 \\
\hline Piko, 2007b Hungary [77] & $548(45.3)$ & 12.2 & $\mathrm{P}+$ & - & 9 \\
\hline Alricsson, 2006 Sweden [78] & $993(51.0)$ & 18.0 & $\mathrm{P}+$ & - & 7 \\
\hline Piko, 2006 Hungary [79] & 1109 & $14-21$ & $\mathrm{P}+$ & - & 7 \\
\hline Watanabe, 2006 Japan [80] & $804(48.9)$ & $3-5$ & $\mathrm{P}+$ & - & 9 \\
\hline Brodersen, 2005 UK [81] & 4320 & 11.8 & $\mathrm{P}+$ & NS & 9 \\
\hline Honkinen, 2005 Finland [82] & 994 & 12 & $\mathrm{P}+$ & - & 10 \\
\hline Erginoz, 2004 Turkey [83] & $4153(47.0)$ & 16.4 & $\mathrm{P}+$ & - & 10 \\
\hline Pastor, 2003 Spain [84] & $1038(50.9)$ & 16.31 & $P+$ & - & 10 \\
\hline Tremblay, 2003 Canada [85] & 12,715 & $12-17$ & $\mathrm{P}+$ & - & 10 \\
\hline Vingilis, 2002 Canada [86] & 1493 & $12-19$ & $\mathrm{P}+$ & - & 10 \\
\hline Thorlindsson, 1990 Iceland [87] & $1131(49.0)$ & $15-16$ & $\mathrm{P}+$ & - & 9 \\
\hline \multicolumn{6}{|l|}{ Longitudinal study } \\
\hline Burdette, 2017 US [28] & 7827 (54.0), 14-year FU & 15.76 (baseline) & $\mathrm{P}+$ & - & 11 \\
\hline Liu, 2015 Japan [88] & 5238 (51.8), 6-year FU & 6 (baseline) & $\mathrm{P}+$ & - & 11 \\
\hline Nigg, 2015 US [89] & 334 (55.1) at FU, 5-year FU & 14.76 (FU) & NS & NS & 8 \\
\hline Spengler, 2014 Germany [90] & 953 (54.5), 6-year FU & 11-17 (baseline) & $\mathrm{P}+$ & NS & 9 \\
\hline Bauldry, 2012 US [91] & 10,375 (53.0), 12-year FU & 15.47 (baseline) & $\mathrm{P}+$ & - & 11 \\
\hline Elinder, 2011 Sweden [92] & 2489 (51.8), 3-year FU & 15.6 (baseline) & $\begin{array}{l}\text { P+ for } \\
\text { boys }\end{array}$ & - & 11 \\
\hline JerdÊn, 2011 Sweden [93] & 1046 (50.3), 2-year FU & 12-14 (baseline) & $\mathrm{P}+$ & - & 10 \\
\hline Breidablik, 2009 Norway [2] & 2399, 4-year FU & 13-19 (baseline) & $P+$ & - & 12 \\
\hline Sacker, 2006 UK [94] & $\begin{array}{c}29,470(49.1), 15 \text { to } 17 \text {-year } \\
\text { FU }\end{array}$ & 16 (baseline) & $P+$ & - & 11 \\
\hline
\end{tabular}

$P A$ physical activity, $S B$ sedentary behaviour, $S R H$ self-rated health, $P+$ positive association, $N$ - negative association, $N S$ not statistically significant association, - not applicable, FU follow up, UK United Kingdom, US United States

\section{Associations between physical activity and self-rated health}

Findings of the included studies in the systematic review Of the 62 studies that examined the association between PA and SRH, most studies $(n=58)$ showed statistically a significant positive association between PA and SRH (see Table 1). Only four studies did not observe a significant relationship between PA and SRH [51, 53, 58, 89]; three used a relatively small sample $[53,58,89]$, and one investigated girls only [53].

A number of studies observed a dose-response relationship between PA and SRH, where an increasing level or amount of PA was related to a higher odds of "good or excellent" SRH (see Additional file 3) [1, 4, 27, 41, 42, $46,48,54,60,68,70,86]$. For example, the study by Lachytova et al. (2017) found in a sample of adolescents 


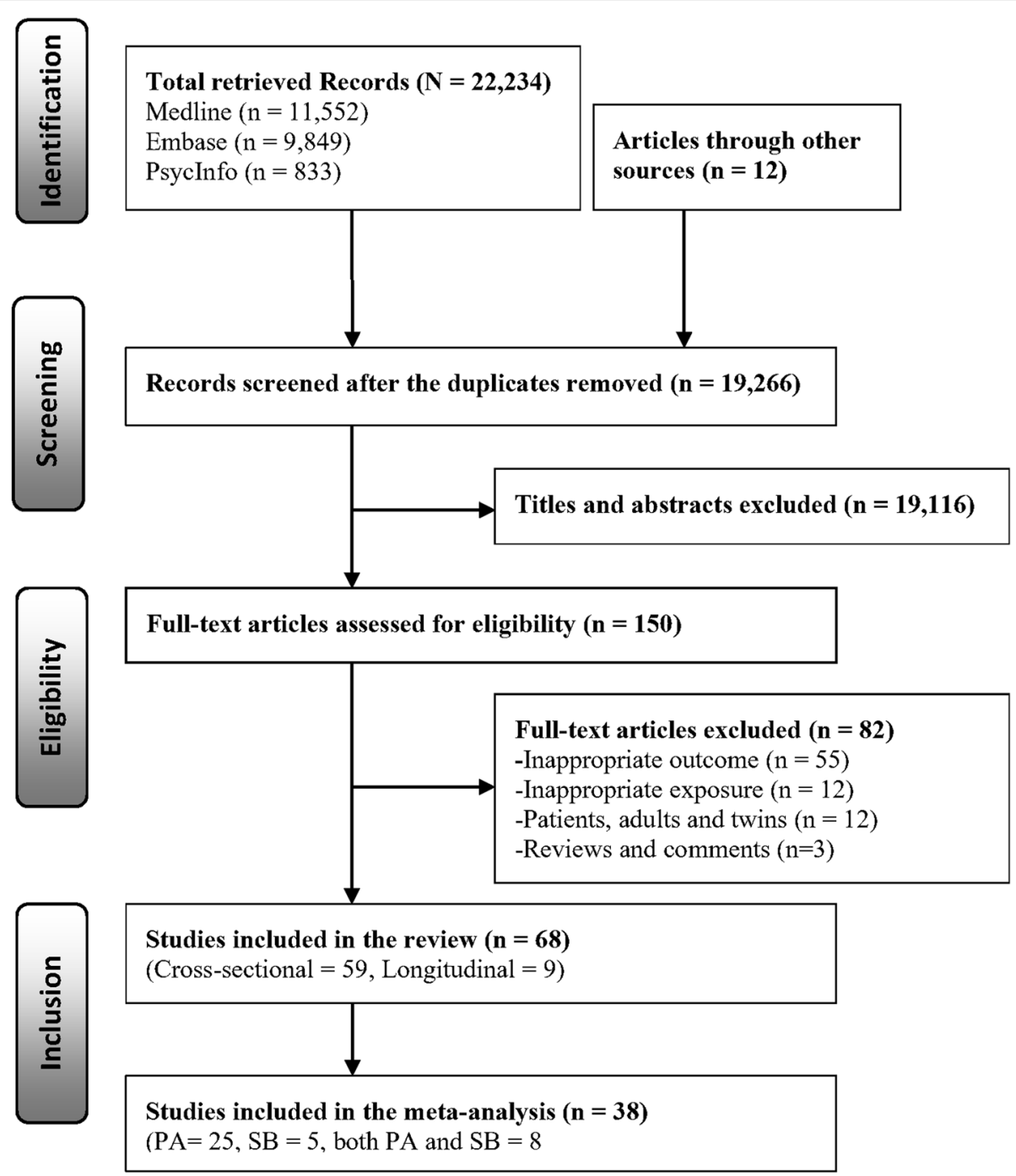

Fig. 1 PRISMA flow diagram for selection of the included studies

aged 14-16 years old that relative to students who exercised less than once a week, students who exercised every day were 8.04 times more likely to report "good and excellent" health; students who exercised 4-6 times a week and 2-3 times a week were 3.67 times and 1.35 times, respectively, more likely than those exercised less than once a week to have "good and excellent" health after adjusting for gender, BMI, mental health and sedentary behaviour in the logistic regression [4]. Herman et al. (2015) reported that Canadian boys who were moderately active or inactive were 1.59 and 2.09 times, respectively, more likely to report lower health than peers who were physically active [1]. The regression adjusted for confounding effects of age, ethnicity, highest household education, smoking status, BMI and screen time. A similar result was observed for girls (adjusted OR $=1.31,95 \%$ CI: 1.09-1.59 for moderately active versus active; adjusted
$\mathrm{OR}=1.99,95 \%$ CI: $1.67-2.36$ for inactive versus active).

Eight out of the nine longitudinal studies observed a significant positive association between higher PA and better SRH. For example, Breidablik et al. (2009) found in a 4year follow-up prospective study in Norway that adolescents who insufficiently engaged in sports and exercise at baseline were more likely to have "poor" health at followup (adjusted OR $=1.64,95 \%$ CI: $1.45-1.86$ ) [2]. Liu et al. (2015) observed that children aged 6 years who maintained regular physical activity in outdoor PA during the 6-year follow-up had higher perceived health at follow-up than their peers who were physically inactive [OR $(95 \%$ CI): 1.37 (1.17-1.60) for total sample; 1.45 (1.14-1.85) for boys; 1.23 (1.00-1.51) for girls] [88]. Sacker et al. (2006) reported in a large British cohort study $(n=15,452)$ that a higher frequency of PA during adolescence predicted better SRH in their adulthood [94]. 


\section{Meta-analysis results for $P A$}

Figure 2 shows the meta-analysis results for 28 studies that investigated the relationship of SRH with PA stratified by PA level. The unadjusted OR in the included studies was used in the meta-analysis. Together, 34 out of the 38 between-group comparisons among studies in the model showed a significant difference in SRH in favour of the higher PA groups. The estimated overall OR (for "poor" health) among all the included studies was 1.76 (95\% CI: 1.60, 1.94) when comparing low PA to moderate or high PA. For those studies that examined more than two levels of PA (low/no PA versus moderate $\mathrm{PA}$, low/no PA versus high PA), the combined OR was 2.13 (95\% CI: 1.73, 2.61), indicating a dose-response effect of PA on health (e.g., higher PA was associated with better health). The studies in the meta-analysis showed high heterogeneity $\left(\mathrm{I}^{2}=93.5 \%, p<0.01\right)$, which may be explained by the differences in the measurement and categorization of PA across studies.

Meta-regression for seven studies with three exposure levels of PA in each study showed that the comparison between low and high PA groups was $77 \%$ more likely to report "poor" SRH (OR $=1.77,95 \%$ CI: $1.16,2.69)$ than the comparison between low and moderate PA groups, indicating a strong dose-response association (M 1, Table 2).

Figure 3 presents the meta-analysis of the relationship of SRH with PA by gender. The pooled OR $(95 \%$ CI) (for "poor" health) between low PA and high/moderate PA was $1.62(1.36,1.93)$ among girls and $1.83(1.52$,

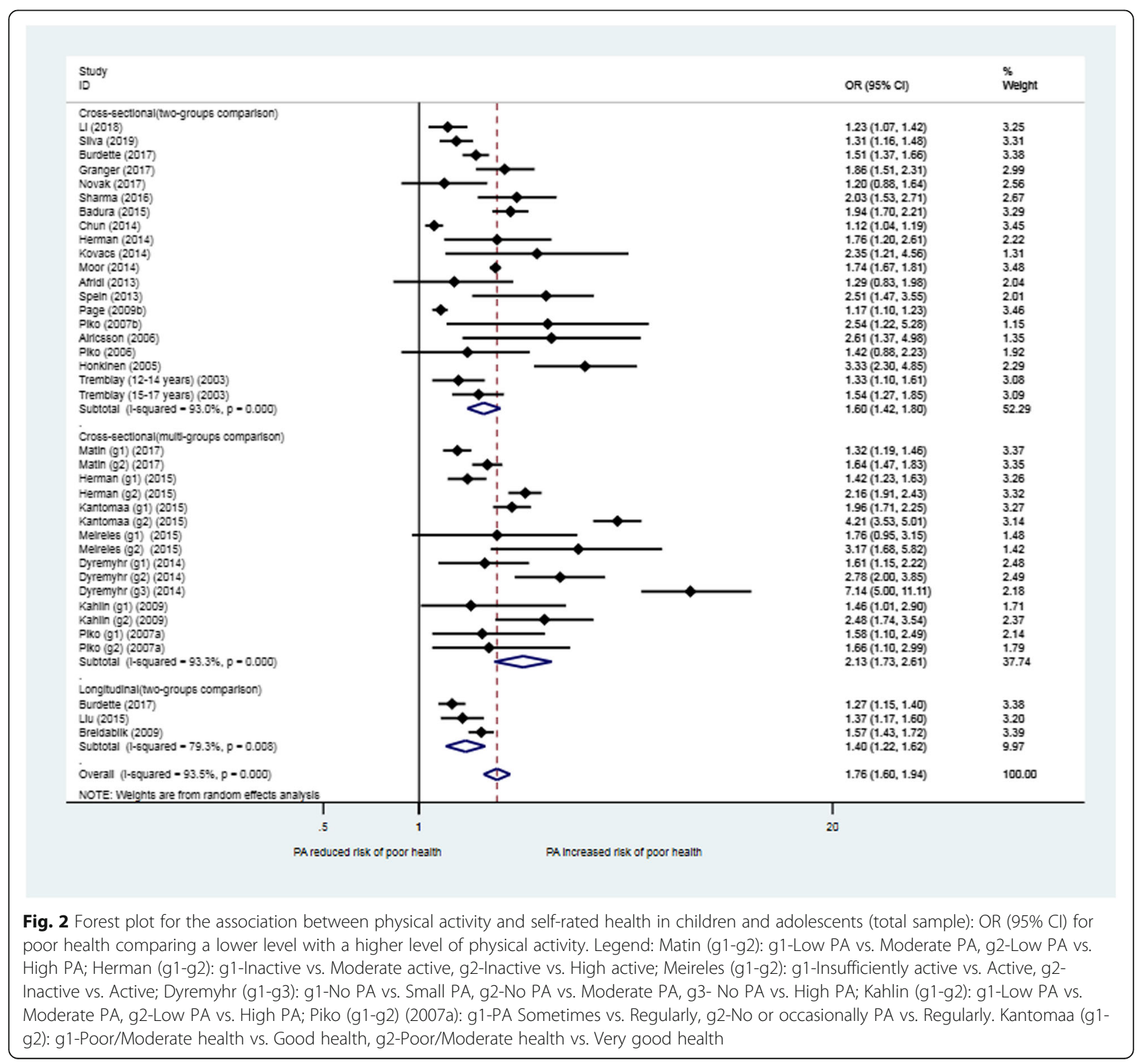


2.19) among boys. Meta-regression showed no significant gender difference in the odds of "poor" SRH across PA levels $(p=0.407)$ (M 2, Table 2).

Egger's test showed no significant risk of publication bias for the studies in the meta-analysis for the total sample $(\alpha=1.53, \mathrm{t}=1.66, p=0.11)$ or for the studies by gender $(\alpha=1.71, \mathrm{t}=0.97, p=0.35$ for boys; $\alpha=1.69, \mathrm{t}=$ $0.95, p=0.36$ for girls). The funnel plots for PA and SRH are presented in Fig. A and Fig. B in the Additional files (see Additional file 4).

\section{Associations between sedentary behaviour and self-rated health}

\section{Findings of the included studies in the systematic review}

Of the 30 studies that examined SB and SRH, 21 studies showed a statistically significant negative relationship between SB and SRH. Nine studies did not find a significant association [35, 40, 48, 51, 63, 65, 81, 89, 90]. Two studies observed a significant relationship between SB and SRH for girls only [3,39], and one study found a significant relationship for boys only [44] (see Table 1).

The relationship between SB and SRH was observed for different types of sedentary behaviours, including watching TV, using computers or playing video games and total screen time. Lachytova et al. (2017) showed that adolescents who watched TV less than two hours a day were more likely to report "good and excellent" health $(\mathrm{OR}=2.36,95 \% \mathrm{CI}: 1.35,4.10)$ than their peers who watched TV two or more hours a day (see Additional file 3) [4]. Husu et al. (2016) used a devicemeasure of SB (accelerometer) and found that a onehour increase in sedentary time a day was related to $29 \%$ lower likelihood of reporting "excellent" health relative to "good/fair/poor" health (OR $=0.71,95 \%$ CI: 0.62 ,
0.82) among children after controlling for the effects of gender and school grade [25]. Herman et al. (2015) observed that adolescent with daily screen time greater than two hours had a higher odds of experiencing "poor" health in comparison with adolescent with daily screen time shorter than two hours $(\mathrm{OR}=1.40,95 \% \mathrm{CI}: 1.19$, 1.66 for boys; OR $=1.50,95 \%$ CI: $1.30,1.74$ for girls) [1].

\section{Meta-analysis results for $S B$}

Figure 4 shows the meta-analysis results for 11 studies that examined the relationship between $\mathrm{SB}$ and SRH. The estimated overall ORs (95\% CIs) for "poor" SRH when comparing higher with lower SB were 1.31 (1.17, 1.46), $1.30(1.20,1.41)$ and $1.25(1.09,1.43)$ for TV viewing, playing computers or video games and total screen time, respectively. There was moderate heterogeneity across all studies in the meta-analysis (overall $\mathrm{I}^{2}=61.5 \%$, $p<0.01$ ), and there was no significant heterogeneity between studies for playing computers and video games $\left(\mathrm{I}^{2}=26.6 \%, p=0.216\right)$. The meta-regression analysis did not show a significant difference in the odds of "poor" SRH among the three different types of SBs (Table 2).

Figure 5 presents the meta-analysis results for the relationship between SB and SRH by gender. The combined OR (95\% CI) (for "poor" health) between high and low $\mathrm{SB}$ was $1.15(1.07,1.24)$ for boys and $1.24(1.12,1.37)$ for girls. Meta-regression did not show a significant gender difference in the effect of SB on SRH $(p=0.353)$ (Table 2).

Egger's test showed no significant risk of publication bias for the studies that investigated the effect of SB $(\alpha=0.38, \mathrm{t}=0.77, p=0.45$ for the total sample; $\alpha=0.26$, $\mathrm{t}=0.28, p=0.79$ for boys; $\alpha=0.70, \mathrm{t}=0.65, p=0.54$ for girls). The funnel plots for SB and SRH are shown in the

Table 2 Meta-regression analysis results for the effect of PA, SB on SRH: odds ratio (OR) and 95\% confidence interval (CI) for poor $\mathrm{SRH}$

\begin{tabular}{|c|c|c|c|c|}
\hline Model & Comparison groups & OR & $95 \% \mathrm{Cl}$ & $\boldsymbol{P}$ value \\
\hline \multirow[t]{3}{*}{$\bar{M} 1$} & PA and SRH (total sample, $n=15$ ) (reference: Moderate PA) & & & \\
\hline & Low vs. High PA & 1.77 & $1.16,2.69$ & 0.012 \\
\hline & Low vs. Moderate PA & 1.57 & $1.15,2.13$ & 0.008 \\
\hline \multirow[t]{3}{*}{ M 2} & PA and SRH (by gender, $n=32$ ) & & & \\
\hline & Girls vs. boys & 0.88 & $0.66,1.19$ & 0.407 \\
\hline & Boys (reference) & 1.84 & $1.49,2.67$ & $<0.001$ \\
\hline \multirow[t]{4}{*}{ M 3} & SB and SRH (total sample, $n=25$ ) (reference: Total screen time) & & & \\
\hline & Computers/video games & 1.05 & $0.85,1.30$ & 0.630 \\
\hline & TV viewing & 1.04 & $0.86,1.27$ & 0.676 \\
\hline & Total screen time & 1.25 & $1.06,1.47$ & 0.010 \\
\hline \multirow[t]{3}{*}{ M 4} & SB and SRH (by gender, $n=18$ ) & & & \\
\hline & Girls vs. boys & 1.07 & $0.92,1.25$ & 0.353 \\
\hline & Boys (reference) & 1.15 & $1.04,1.29$ & 0.013 \\
\hline
\end{tabular}

Bold values for $p$ value in the table indicate statistical significance $(p<0.05)$ 


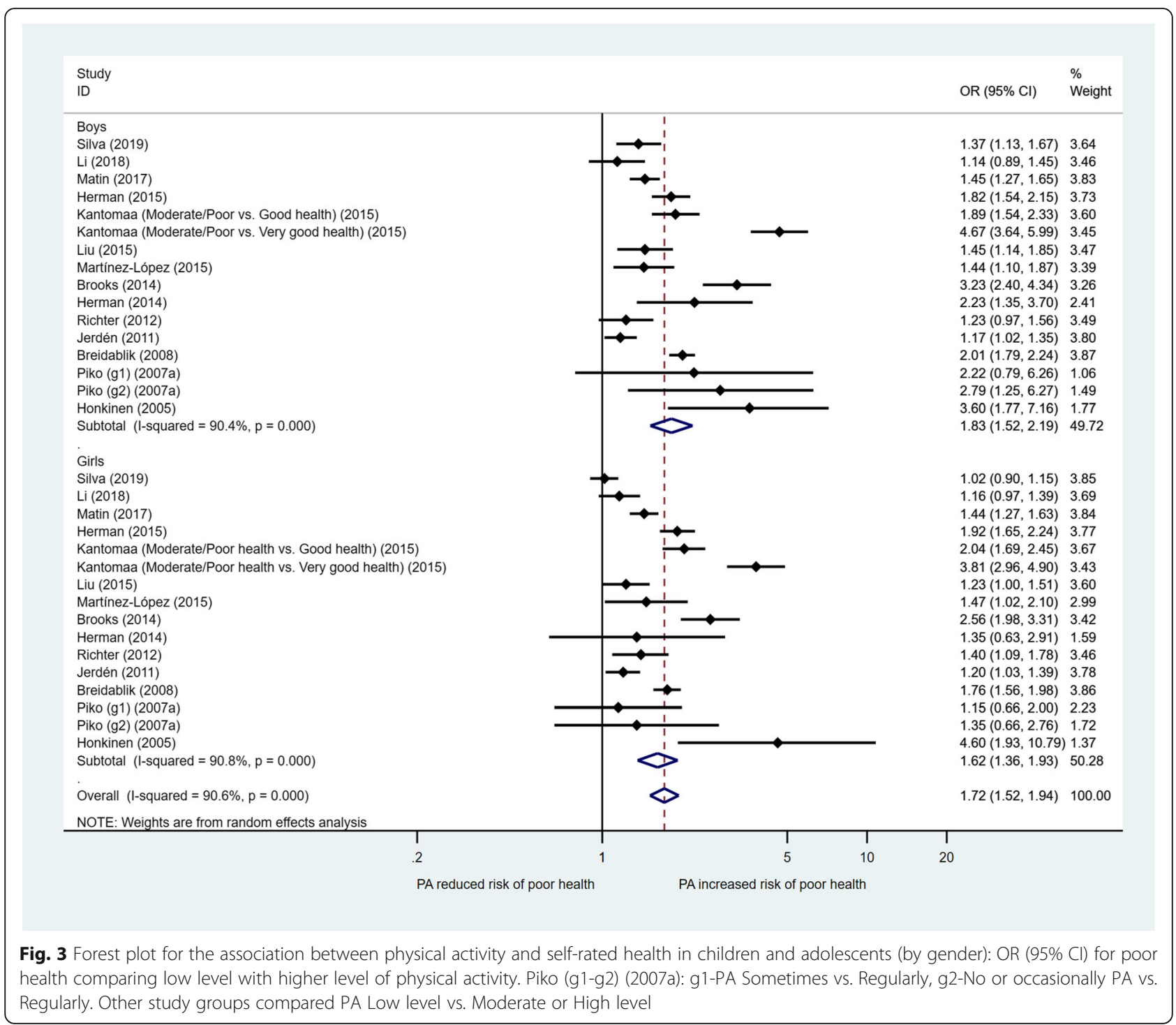

Additional files (see Fig. $\mathrm{C}$ and Fig. D in Additional file $4)$.

\section{Discussion}

This systematic review found strong evidence for a positive relationship between physical activity and SRH and a negative relationship between sedentary behaviour and SRH among children and adolescents. The associations were observed in both cross-sectional and longitudinal studies. We found evidence of a significant doseresponse association between PA and self-rated health. The observed associations between PA, SB and SRH appear independent of gender, age, body weight status, mental health and household socio-economic status among children and adolescents.

To the best of our knowledge, this is the first study that systematically synthesized the associations of SRH with PA and SB among younger populations of children and adolescents. Positive associations between PA and SRH and inverse associations between $\mathrm{SB}$ and $\mathrm{SRH}$ have been demonstrated among adults and older people [22, 24, 95, 96]. The finding in the present study is consistent with previous studies demonstrating positive relationships between PA and SRH among adults $[22,24,95,96]$. Eight out of the nine included longitudinal studies found a positive association between PA and SRH, suggesting that PA among children and adolescents may predict future health status in adolescence and adulthood. The findings from this study add to the literature for detecting a dose-response association between increasing levels of PA and elevated perceived health among children and youth. The association appears to be in a log-linear increasing trend between PA levels and $\mathrm{SRH}$, and this dose-response pattern was found for both boys and girls. 


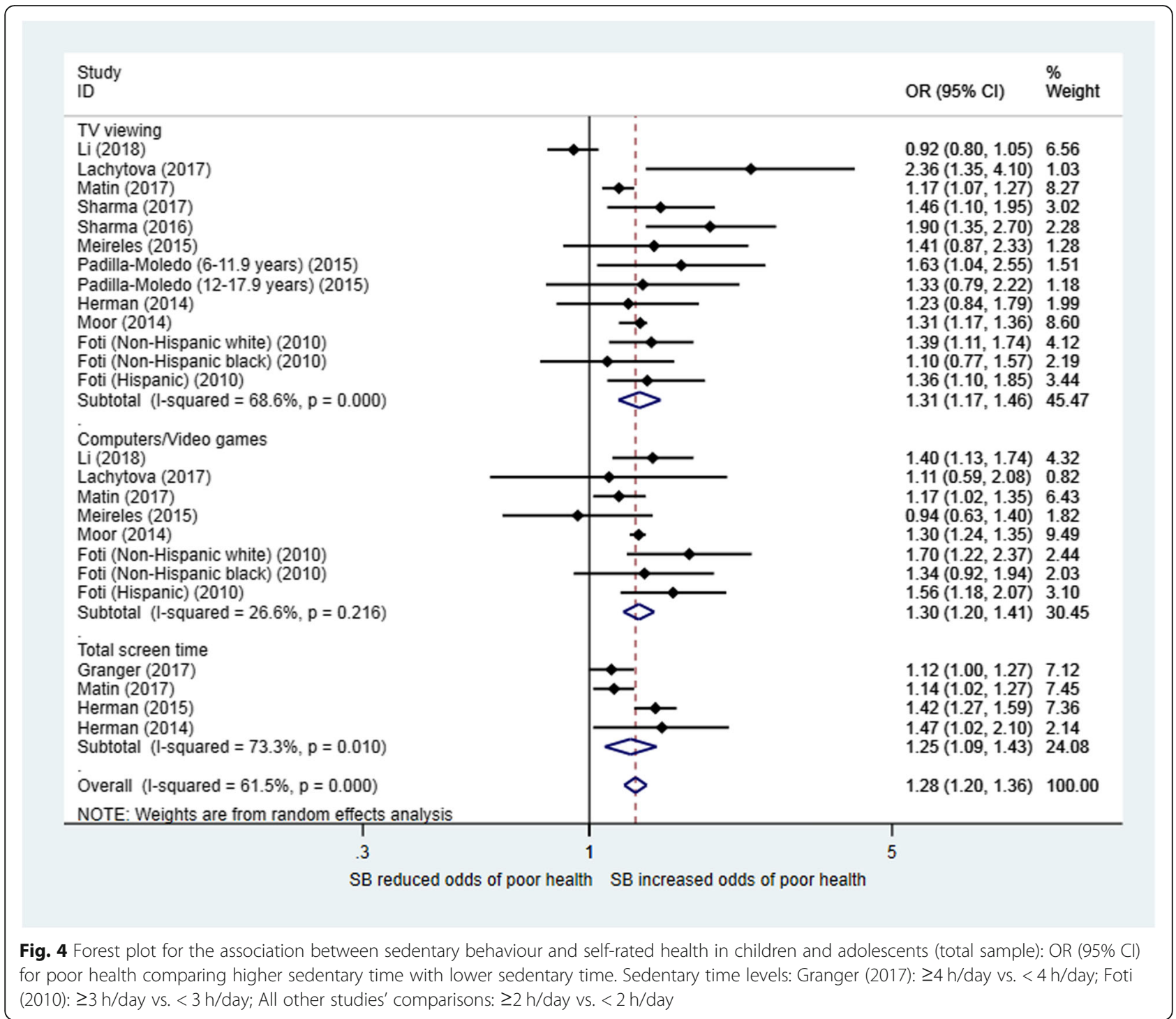

The present study found a consistent association between different forms of SBs (TV viewing, playing computers or video games and total screen time) and lower SRH among children and adolescents. Children and adolescents who spent more time on a SB (e.g., $\geq 2 \mathrm{~h} /$ day versus $<2 \mathrm{~h} /$ day) were more likely to experience poor $\mathrm{SRH}$. There was no significant difference in the association by gender (Fig. 5) or by SB type. As most of the studies categorized SB in two levels ( $\geq 2 \mathrm{~h}$ /day versus $<2$ $\mathrm{h} /$ day) in the regression analysis, we were not able to examine the dose-response effect by comparing more than two levels for SB using meta-analysis due to the sparse availability of data.

One of the innovative aspects of the present review is that we analysed both PA and SB exposures and included population-based studies with large samples. This enabled us to examine whether the effects of PA and SB on health outcomes were independent of each other and of other confounding variables. Since multivariable regression analyses adjusted for a number of confounders, such as demographics (e.g., gender, age), household economic factors, BMI, mental health problems and parental factors (e.g., education, smoking, health), the observed correlations among PA, SB and SRH can be considered robust regardless of gender, age, socioeconomic factors, body weight status and mental health among children and youth. Some studies simultaneously adjusted $\mathrm{PA}$ and $\mathrm{SB}$ variables in the regression analysis $[1-4,26,67,72]$, hence, the effect PA and SB for SRH may be regarded as mutually independent.

Additionally, we detected the magnitude of differences in self-rated health between PA or SB comparison groups and found that the difference in some studies exceeded a minimally important difference (MID) value [97], defined as a clinically meaningful difference in health status that may signify a practical importance for 


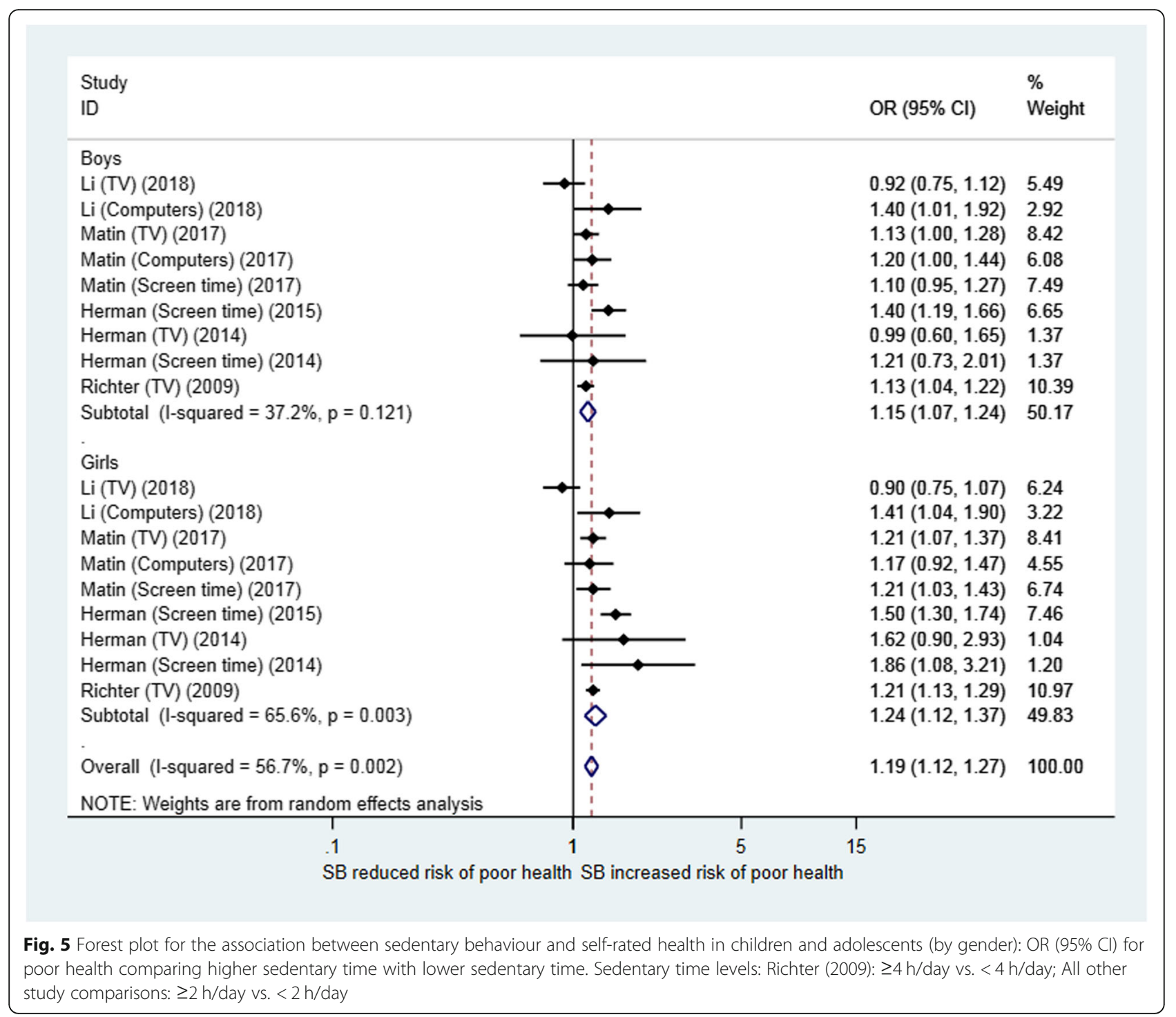

modifying public health interventions among children and adolescents. The MID criterion varies across health status measures and the type of statistics for the association of interest. In terms of the effect size value using an odds ratio for a binary categorical outcome, prior research suggests that a log odds greater than 2.0 or less than 0.5 is considered a large effect size [98]. A number of studies reported an odds ratio above 2.0 or below 0.5 $[1,3,4,39,43,46,54,60,68,79,82]$, suggesting a large effect size.

The findings in this study further reinforce the existing evidence by showing that a single-item question of selfrated health is a sensitive and valid indicator for general health in school-aged children and adolescents. Previous studies have demonstrated that poor SRH in adolescence is related to prescribed medication in adulthood [99] and is a risk factor for elevated morbidity and mortality $[91,100]$. The observation in the present review strengthens the discriminative validity of the self-rated health reported by children and youth. Subject or patient self-reported outcome measures have been increasingly used to evaluate health status among general populations as well as patients with various diseases $[9,13]$. The single item of SRH has been frequently used together with multi-component quality of life measures (e.g., the SF-36) to assess overall health or its relationship with physical and psychological health among adults [101] and is a useful tool in large population surveys to monitor the health of populations and study the effects of various socio-economic risk factors and health-related behaviours [95, 96]. This study highlights the utility of the single-item SRH among children and adolescents. Future research is encouraged to expand investigations on the role of SRH in predicting physical and mental morbidities among children and adolescents, as previously demonstrated among adults $[5,6]$. 
Due to the heterogeneity in the measurement of PA and $\mathrm{SB}$ and in the statistical methods (e.g., the regression method), we performed meta-analyses for the studies with comparable data that used logistic regressions to quantify the associations between the exposures and health outcomes. We included a relatively large number of studies in the meta-analysis. For the studies reporting frequencies of SRH for different categories of PA and $\mathrm{SB}$, we calculated the odds ratios and the confidence intervals for the synthesis in meta-analyses. A few studies used other statistical methods, such as linear regression, t-test or ANOVA and were not included in the metaanalysis due to the heterogeneity in statistics and small number of studies. Regarding the effect of PA, several studies used lower SRH as a reference group (e.g., coded as "good/excellent" versus "poor/fair" health) with more than two levels of PA in the logistic regression and were not included in the meta-analysis due to the difference in the grouping of PA (e.g., PA as clusters or days/week) $[4,27,42,45,60]$.

The strengths of this review include a comprehensive literature search in both the published and grey literatures and stringent methodology adhering to the PRIS MA statement, the inclusion of both PA and SB, the use of meta-regression analysis, and the inclusion of large sample studies with diversified socio-economic/sociodemographic backgrounds of children and adolescents. Population-based studies with large samples allowed to perform a multivariable regression analysis, enabling robust parameter estimates for inference to target populations. Large-sample studies yield narrower confidence intervals for the estimated parameters, thus providing more precise results than small-sample studies. Metaregression analysis allowed us to test subgroup differences in health outcomes by gender, the PA dose level and the type of SBs among the participants. Additionally, the studies included in the present review were conducted in a wide range of countries and regions; hence, the findings in this review may be generalizable to broad regions in the world. While we made efforts to search and include grey literature, we did not include unpublished literature because only one thesis was identified as eligible. We do not expect that the grey literature would change the results, as previous studies have shown that the exclusion of unpublished studies and dissertations/ theses had little influence on the estimates of health outcomes in a systematic review [102]. It is recommended that the inclusion of grey literature in a systematic review should be considered in those areas where there are very few published studies $[102,103]$.

This review is limited by the small number of longitudinal studies included, affecting the inference about the direction of the association between PA, SB and SRH. More longitudinal and prospective studies and intervention are needed to study the characteristics of this relationship. In addition, the assessment of PA and $\mathrm{SB}$ in the included studies was largely based on selfreport, which is prone to be affected by measurement errors. Studies using device measures of PA and SB are required to assess more accurately the relationship between PA, SB and SRH among children and youth.

\section{Conclusions}

This study found that higher PA is associated with better SRH and excessive SB is related to poor SRH in adolescents and children. The study reveals that there is a positive and dose-response association between PA and $\mathrm{SRH}$ in children and adolescents. These findings suggest that school-based programmes promoting active lifestyles and reducing SB may enhance the health status of children and adolescents. Public health policy and practice should prioritize interventions for both PA and SB tailored to children and adolescents with unhealthy behaviours to increase and maximize their health benefits.

\section{Supplementary information}

Supplementary information accompanies this paper at https://doi.org/10. 1186/s12889-020-09447-1.

Additional file 1. Literature search strategy used in the databases of MEDLINE, EMBASE and PSYCINFO.

Additional file 2. References of the excluded studies from the full-text review.

Additional file 3. Study characteristics, assessments of PA, SB and SRH, and the main findings.

Additional file 4. Fig. A-D funnel plots: comparisons of the odds of "poor" SRH by PA and SB.

\section{Abbreviations}

SRH: Self-rated health; PA: Physical activity; SB: Sedentary behaviour; PRIS MA: Preferred Reporting Items for Systematic reviews and Meta-Analyses; HRQOL: Health-related quality of life; OR: Odds ratio; Cl: Confidence interval

\section{Acknowledgements}

Not applicable.

\section{Authors' contributions}

XYW designed the study, performed the literature search and study selection, data extraction and statistical analyses, and wrote the draft of the manuscript. TZH performed the study selection, data extraction, statistical analyses, and wrote the draft of the manuscript. GHL contributed to the study selection and revisions of the manuscript. All authors participated in the critical revisions of the manuscript. All authors read and approved the final version of the manuscript.

\section{Funding}

The present study was supported by a research awards to Xiuyun $\mathrm{Wu}$, that was provided by Weifang Medical University (Grant No: 2017BSQD61). The interpretations and opinions in the present study are those of the authors. The funders had no role in study design, data collection and analysis, or preparation of the manuscript.

Availability of data and materials

All data are available in the manuscript and in the supporting information. 


\section{Ethics approval and consent to participate}

Not applicable.

\section{Consent for publication}

Not applicable.

\section{Competing interests}

The authors declared no competing interests.

Received: 26 April 2020 Accepted: 25 August 2020

Published online: 03 September 2020

\section{References}

1. Herman KM, Hopman WM, Sabiston CM. Physical activity, screen time and self-rated health and mental health in Canadian adolescents. Prev Med. 2015;73:112-6.

2. Breidablik HJ, Meland E, Lydersen S. Self-rated health during adolescence: stability and predictors of change (young-HUNT study, Norway). Eur J Pub Health. 2009;19(1):73-8.

3. Herman KM, Sabiston CM, Tremblay A, Paradis G. Self-rated health in children at risk for obesity: associations of physical activity, sedentary behaviour, and BMI. J Phys Act Health. 2014;11(3):543-52.

4. Lachytova M, Katreniakova Z, Mikula P, Jendrichovsky M, Nagyova I. Associations between self-rated health, mental health problems and physical inactivity among urban adolescents. Eur J Pub Health. 2017;27(6): 984-9.

5. Burström B, Fredlund P. Self rated health: is it as good a predictor of subsequent mortality among adults in lower as well as in higher social classes? J Epidemiol Community Health. 2001;55(11):836-40.

6. Halford C, Wallman T, Welin L, Rosengren A, Bardel A, Johansson S, et al. Effects of self-rated health on sick leave, disability pension, hospital admissions and mortality. A population-based longitudinal study of nearly 15,000 observations among Swedish women and men. BMC Public Health. 2012;12:1103.

7. Vie TL, Hufthammer KO, Holmen TL, Meland E, Breidablik HJ. Is self-rated health a stable and predictive factor for allostatic load in early adulthood? Findings from the Nord Trondelag health study (HUNT). Soc Sci Med. 2014; 117:1-9.

8. Ekelund U, Tarp J, Steene-Johannessen J, Hansen BH, Jefferis B, Fagerland MW, et al. Dose-response associations between accelerometry measured physical activity and sedentary time and all cause mortality: systematic review and harmonised meta-analysis. BMJ. 2019;366:14570.

9. Bize R, Johnson JA, Plotnikoff RC. Physical activity level and health-related quality of life in the general adult population: a systematic review. Prev Med. 2007:45(6):401-15.

10. Prentice-Dunn H, Prentice-Dunn S. Physical activity, sedentary behavior, and childhood obesity: a review of cross-sectional studies. Psychol Health Med. 2012;17(3):255-73.

11. Biddle SJ, Asare M. Physical activity and mental health in children and adolescents: a review of reviews. Br J Sports Med. 2011;45(11):886-95.

12. Janssen I, Leblanc AG. Systematic review of the health benefits of physical activity and fitness in school-aged children and youth. Int J Behav Nutr Phys Act. 2010;7:40.

13. Wu XY, Han LH, Zhang JH, Luo S, Hu JW, Sun K. The influence of physical activity, sedentary behavior on health-related quality of life among the general population of children and adolescents: a systematic review. PLoS One. 2017;12(11):e0187668.

14. Andersen LB, Riddoch C, Kriemler S, Hills AP. Physical activity and cardiovascular risk factors in children. Br J Sports Med. 2011:45(11):871-6.

15. Fung C, Kuhle S, Lu C, Purcell M, Schwartz M, Storey K, et al. From "best practice" to "next practice": the effectiveness of school-based health promotion in improving healthy eating and physical activity and preventing childhood obesity. Int J Behav Nutr Phys Act. 2012;9:27.

16. Sedentary Behaviour Research Network. Letter to the editor: standardized use of the terms "sedentary" and "sedentary behaviours". Appl Physiol Nutr Metab. 2012;37(3):540-2.

17. Suchert V, Hanewinkel $R$, Isensee B. Sedentary behavior and indicators of mental health in school-aged children and adolescents: a systematic review. Prev Med. 2015;76:48-57.
18. Stanczykiewicz B, Banik A, Knoll N, Keller J, Hohl DH, Rosińczuk J, et al. Sedentary behaviors and anxiety among children, adolescents and adults: a systematic review and meta-analysis. BMC Public Health. 2019;19(1):459.

19. Page AS, Cooper AR, Griew $P$, Jago R. Children's screen viewing is related to psychological difficulties irrespective of physical activity. Pediatrics. 2010; 126(5):e1011-7.

20. Hancox RJ, Milne BJ, Poulton R. Association between child and adolescent television viewing and adult health: a longitudinal birth cohort study. Lancet. 2004;364(9430):257-62.

21. Zarini GG, Vaccaro JA, Canossa Terris MA, Exebio JC, Tokayer L, Antwi J, et al. Lifestyle behaviors and self-rated health: the living for health program. J Environ Public Health. 2014;2014:315042.

22. Riediger ND, Bombak AE, Mudryj AN. Health-related behaviours and their relationship with self-rated health among Canadian adults. BMC Public Health. 2019;19(1):960.

23. von Rosen P, Hagstromer M. Excellent self-rated health associated with activities of higher intensities: a compositional data analysis approach. J Phys Act Health. 2019:1-7.

24. Liangruenrom N, Craike M, Biddle SJH, Suttikasem K, Pedisic Z. Correlates of physical activity and sedentary behaviour in the Thai population: a systematic review. BMC Public Health. 2019;19(1):414.

25. Husu P, Vaha-Ypya H, Vasankari T. Objectively measured sedentary behavior and physical activity of Finnish 7- to 14-year-old children- associations with perceived health status: a cross-sectional study. BMC Public Health. 2016;16: 338.

26. Sharma B, Cosme Chavez R, Jeong AS, Nam EW. Television viewing and its association with sedentary behaviors, self-rated heath and academic performance among secondary school students in Peru. Int J Environ Res Public Health. 2017;14(4):383.

27. Novak D, Stefan L, Emeljanovas A, Mieziene B, Milanovic I, Janic SR, et al. Factors associated with good self-rated health in European adolescents: a population-based cross-sectional study. Int J Public Health. 2017;62(9):971-9.

28. Burdette AM, Needham BL, Taylor MG, Hill TD. Health lifestyles in adolescence and self-rated health into adulthood. J Health Soc Behav. 2017; 58(4):520-36.

29. Moher D, Liberati A, Tetzlaff J, Altman DG. Preferred reporting items for systematic reviews and meta-analyses: the PRISMA statement. BMJ. 2009; 339:b2535.

30. Choudhury M. The relationship between in-school physical activity and life satisfaction, self-rated health, academic performance, and out-of-school physical activity: a Canadian study. Queen's University, Kingston, Ontario, Canada; 2011

31. Higgins JP, Thompson SG, Deeks JJ, Altman DG. Measuring inconsistency in meta-analyses. BMJ. 2003;327(7414):557-60.

32. Song F, Khan KS, Dinnes J, Sutton AJ. Asymmetric funnel plots and publication bias in meta-analyses of diagnostic accuracy. Int J Epidemiol. 2002;31(1):88-95.

33. Egger M, Davey Smith G, Schneider M, Minder C. Bias in meta-analysis detected by a simple, graphical test. BMJ. 1997;315(7109):629-34.

34. Quality Assessment Tool for Observational Cohort and Cross-Sectional Studies. Study Quality Assessment Tools. The National Heart, Lung, and Blood Institute, NIH. https://www.nhlbi.nih.gov/health-topics/study-qualityassessment-tools.

35. Marques A, Peralta M, Santos T, Martins J, Gaspar de Matos M. Self-rated health and health-related quality of life are related with adolescents' healthy lifestyle. Public Health. 2019;170:89-94.

36. Silva AOD, Diniz PRB, Santos MEP, Ritti-Dias RM, Farah BQ, Tassitano RM et al. Health self-perception and its association with physical activity and nutritional status in adolescents. J Pediatr. 2019;95(4):458-65.

37. Jodkowska M, Oblacinska A, Dzielska A, Nalecz H, Fijalkowska A. Behavioural factors as predictors of self-rated health among polish adolescent girls. Dev Period Med. 2019;23(2):109-16.

38. Werneck AO, Silva DR, Agostinete RR, Fernandes RA, Ronque ERV, Oyeyemi $\mathrm{AL}$, et al. Relationship of parental and Adolescents' screen time to self-rated health: a structural equation modeling. Health Educ Behav. 2018;45(5):76471.

39. Li W, Sekine M, Yamada M, Fujimura Y, Tatsuse T. Lifestyle and overall health in high school children: results from the Toyama birth cohort study, Japan. Pediatr Int. 2018;60(5):467-73.

40. Granger E, Williams G, Di Nardo F, Harrison A, Verma A. The relationship between physical activity and self-rated health status in European 
adolescents: Results of the EURO-URHIS 2 survey. Eur J Public Health. 2017; 27(suppl_2):107-11.

41. Matin N, Kelishadi R, Heshmat R, Motamed-Gorji N, Djalalinia S, Motlagh ME, et al. Joint association of screen time and physical activity on self-rated health and life satisfaction in children and adolescents: the CASPIAN-IV study. Int Health. 2017;9(1):58-68.

42. Koelmeyer R, Currier D, Spittal MJ, Schlichthorst M, Pirkis JE, English DR. Age matters: exploring correlates of self-rated health across four generations of Australian males. Behav Med. 2016;42(3):132-42.

43. Sharma B, Nam EW, Kim D, Yoon YM, Kim Y, Kim HY. Role of gender, family, lifestyle and psychological factors in self-rated health among urban adolescents in Peru: a school-based cross-sectional survey. BMJ Open. 2016;6(2):e010149.

44. Ustinavičienè R, Škèmienè L, Lukšienè D, Radišauskas R, Kalinienè G, Vasilavičius P. Problematic computer game use as expression of internet addiction and its association with self-rated health in the Lithuanian adolescent population. Medicina. 2016;52(3):199-204.

45. Badura P, Geckova AM, Sigmundova D, van Dijk JP, Reijneveld SA. When children play, they feel better: organized activity participation and health in adolescents. BMC Public Health. 2015;15:1090.

46. Kantomaa MT, Tammelin T, Ebeling H, Stamatakis E, Taanila A. High levels of physical activity and cardiorespiratory fitness are associated with good selfrated health in adolescents. J Phys Act Health. 2015;12(2):266-72.

47. Martínez-López EJ, Hita-Contreras F, Moral-García JE, Grao-Cruces A, Ruiz JR, Redecillas-Peiró MT, et al. Association of low weekly physical activity and sedentary lifestyle with self-perceived health, pain, and well-being in a Spanish teenage population. Sci Sports. 2015;30(6):342-51.

48. Meireles AL, Xavier CC, Proietti FA, Caiaffa WT. Influence of individual and socio-environmental factors on self-rated health in adolescents. Rev Bras Epidemiol. 2015;18(3):538-51.

49. Padilla-Moledo C, Castro-Pinero J, Ortega FB, Pulido-Martos M, Sjostrom M, Ruiz JR. Television viewing, psychological positive health, health complaints and health risk behaviors in Spanish children and adolescents. J Sports Med Phys Fitness. 2015;55(6):675-83.

50. Novak D, Suzuki E, Kawachi I. Are family, neighbourhood and school social capital associated with higher self-rated health among Croatian high school students? A population-based study. BMJ Open. 2015;5(6):e007184.

51. Smith NR, Lewis DJ, Fahy A, Eldridge S, Taylor SJ, Moore DG, et al. Individual socio-demographic factors and perceptions of the environment as determinants of inequalities in adolescent physical and psychological health: the Olympic regeneration in East London (ORiEL) study. BMC Public Health. 2015;15:150.

52. Chun J, Nam S, Chung IJ, Kang H, Nho CR, Woo S. Factors associated with perceived health among Korean adolescents. Soc Work Public Health. 2014; 29(6):528-39.

53. Craike MJ, Polman R, Eime R, Symons C, Harvey J, Payne W. Associations between behavior regulation, competence, physical activity, and health for adolescent females. J Phys Act Health. 2014;11 (2):410-8.

54. Dyremyhr AE, Diaz E, Meland E. How adolescent subjective health and satisfaction with weight and body shape are related to participation in sports. J Environ Public Health. 2014;2014:851932.

55. Kovacs E, Piko BF, Keresztes N. The interacting role of physical activity and diet control in Hungarian adolescents' substance use and psychological health. Subst Use Misuse. 2014;49(10):1278-86.

56. Moor I, Rathmann K, Stronks K, Levin K, Spallek J, Richter M. Psychosocial and behavioural factors in the explanation of socioeconomic inequalities in adolescent health: a multilevel analysis in 28 European and north American countries. J Epidemiol Community Health. 2014;68(10):912-21.

57. Brooks FM, Smeeton NC, Chester K, Spencer N, Klemera E. Associations between physical activity in adolescence and health behaviours, well-being, family and social relations. Int J Health Promot Educ. 2014;52(5):271-82.

58. Afridi AA, Motwani K, Khawaja S, Khoja AA, Fatmi Z, Azam I, et al. Selfperceived health among school going adolescents in Pakistan: influence of individual, parental and life style factors? Glob J Health Sci. 2013;5(4):71-8.

59. Do YK, Shin E, Bautista MA, Foo K. The associations between self-reported sleep duration and adolescent health outcomes: what is the role of time spent on internet use? Sleep Med. 2013;14(2):195-200.

60. Galán I, Boix R, Medrano MJ, Ramos P, Rivera F, Pastor-Barriuso R, et al. Physical activity and self-reported health status among adolescents: a crosssectional population-based study. BMJ Open. 2013;3(5):e002644.

61. Spein AR, Pedersen CP, Silviken AC, Melhus M, Kvernmo SE, Bjerregaard P. Self-rated health among Greenlandic Inuit and Norwegian Sami adolescents: associated risk and protective correlates. Int J Circumpolar Health. 2013. p. 72. https://doi.org/10.3402/ijch.v72i0.19793.

62. Richter M, Moor I, van Lenthe FJ. Explaining socioeconomic differences in adolescent self-rated health: the contribution of material, psychosocial and behavioural factors. J Epidemiol Community Health. 2012;66(8):691-7.

63. Tabak I, Oblacinska A, Jodkowska M. Physical activity and sedentary behaviour as predictors of adolescent health in rural and urban environments in Poland. Phys Cult Sport Stud Res. 2012;54:68-77.

64. Veloso SM, Matos MG, Carvalho M, Diniz JA. Psychosocial factors of different health behaviour patterns in adolescents: association with overweight and weight control behaviours. J Obes. 2012;2012:852672.

65. Zullig KJ, White RJ. Physical activity, life satisfaction, and self-rated health of middle school students. Appl Res Qual Life. 2011;6(3):277-89.

66. Foti K, Eaton D. Associations of selected health risk behaviors with self-rated health status among U.S. high school students. Public Health Rep. 2010; 125(5):771-81.

67. lannotti RJ, Janssen I, Haug E, Kololo H, Annaheim B, Borraccino A, et al. Interrelationships of adolescent physical activity, screen-based sedentary behaviour, and social and psychological health. Int J Public Health. 2009; 54(Suppl 2):191-8.

68. Kahlin Y, Werner S, Romild U, Alricsson M. Self-related health, physical activity, BMl and musculoskeletal complaints: a comparison between foreign and Swedish high school students. Int J Adolesc Med Health. 2009; 21:327-41.

69. Mathers M, Canterford L, Olds T, Hesketh K. Electronic media use and adolescent health and well-being: cross-sectional community study. Acad Pediatr. 2009;9(5):307-14.

70. Page RM, Suwanteerangkul J. Self-rated health, psychosocial functioning, and health-related behavior among Thai adolescents. Pediatr Int. 2009a; 51(1):120-5.

71. Page R, Simonek J, Ihász F, Hantiu I, Uvacsek M, Kalabiska I, et al. Self-rated health, psychosocial functioning, and other dimensions of adolescent health in central and eastern European adolescents. Eur J Psychiat. 2009b;23(2): $101-14$.

72. Richter M, Erhart M, Vereecken CA, Zambon A, Boyce W, Nic GS. The role of behavioural factors in explaining socio-economic differences in adolescent health: a multilevel study in 33 countries. Soc Sci Med. 2009;69(3):396-403.

73. Breidablik HJ, Meland E, Lydersen S. Self-rated health in adolescence: a multifactorial composite. Scand J Public Health. 2008;36(1):12-20.

74. Sodergvist F, Carlberg M, Hardell L. Use of wireless telephones and selfreported health symptoms: a population-based study among Swedish adolescents aged 15-19 years. Environ Health. 2008;7:18.

75. Kelleher CC, Tay J, Gabhainn SN. Influence on self-rated health of sociodemographic, lifestyle and affluence factors: an analysis of the Irish and international health Behaviours among school-aged children (HBSC) datasets 1998. Ir Med J. 2007;100(8):43-6.

76. Piko BF. Self-perceived health among adolescents: the role of gender and psychosocial factors. Eur J Pediatr. 2007a;166(7):701-8.

77. Piko BF, Keresztes N. Self-perceived health among early adolescents: role of psychosocial factors. Pediatr Int 2007b;49(5):577-583.

78. Alricsson M, Landstad BJ, Romild U, Werner S. Self-related health, physical activity and complaints in Swedish high school students. Sci World J. 2006; 6:816-26.

79. Piko BF, Keresztes N. Physical activity, psychosocial health and life goals among youth. J Community Health. 2006;31(2):136-45.

80. Watanabe M, Nakamura K, Fukuda Y, Takano T. Association of parental and children behaviors with the health status of preschool children. Prev Med. 2006;42(4):297-300.

81. Brodersen NH, Steptoe A, Williamson S, Wardle J. Sociodemographic, developmental, environmental, and psychological correlates of physical activity and sedentary behavior at age 11 to 12. Ann Behav Med. 2005;29:2-11.

82. Honkinen PL, Suominen SB, Valimaa RS, Helenius HY, Rautava PT. Factors associated with perceived health among 12-year-old school children. Relevance of physical exercise and sense of coherence. Scand J Public Health. 2005;33(1):35-41.

83. Erginoz E, Alikasifoglu M, Ercan O, Uysal O, Ercan G, Albayrak Kaymak D, et al. Perceived health status in a Turkish adolescent sample: risk and protective factors. Eur J Pediatr. 2004;163(8):485-94.

84. Pastor Y, Balaguer I, Pons D, García-Merita M. Testing direct and indirect effects of sports participation on perceived health in Spanish adolescents between 15 and 18 years of age. J Adolesc. 2003;26(6):717-30. 
85. Tremblay S, Dahinten S, Kohen D. Factors related to adolescents' selfperceived health. Health Rep. 2003;14(Supp I):7-16.

86. Vingilis ER, Wade TJ, Seeley JS. Predictors of adolescent self-rated health. Analysis of the National Population Health Survey. Can J Public Health. 2002; 93(3):193-7.

87. Thorlindsson T, Vilhjalmsson R, Valgeirsson G. Sport participation and perceived health status: a study of adolescents. Soc Sci Med. 1990;31(5): $551-6$.

88. Liu J, Sekine M, Tatsuse T, Fujimura Y, Hamanishi S, Lu F, et al. Outdoor physical activity and its relation with self-reported health in Japanese children: results from the Toyama birth cohort study. Child Care Health Dev. 2015;41(6):920-7.

89. Nigg CR, Amato K. The influence of health behaviors during childhood on adolescent health behaviors, health indicators, and academic outcomes among participants from Hawaii. Int J Behav Med. 2015;22(4):452-60.

90. Spengler S, Mess F, Schmocker E, Woll A. Longitudinal associations of health-related behavior patterns in adolescence with change of weight status and self-rated health over a period of 6 years: results of the MoMo longitudinal study. BMC Pediatr. 2014;14:242.

91. Bauldry S, Shanahan MJ, Boardman JD, Miech RA, Macmillan R. A life course model of self-rated health through adolescence and young adulthood. Soc Sci Med. 2012;75(7):1311-20.

92. Elinder LS, Sundblom E, Rosendahl KI. Low physical activity is a predictor of thinness and low self-rated health: gender differences in a Swedish cohort. J Adolesc Health. 2011:48(5):481-6.

93. Jerden L, Burell G, Stenlund H, Weinehall L, Bergstrom E. Gender differences and predictors of self-rated health development among Swedish adolescents. J Adolesc Health. 2011:48(2):143-50.

94. Sacker A, Cable N. Do adolescent leisure-time physical activities foster health and well-being in adulthood? Evidence from two British birth cohorts. Eur J Pub Health. 2006;16(3):332-6.

95. Sodergren M, McNaughton SA, Salmon J, Ball K, Crawford DA. Associations between fruit and vegetable intake, leisure-time physical activity, sitting time and self-rated health among older adults: cross-sectional data from the WELL study. BMC Public Health. 2012;12:551.

96. Gomez-Baya D, Salinas-Perez JA, Rodero-Cosano ML, Alvarez-Galvez J. Socioeconomic inequalities in health through lifestyles: Analysing gender and age differences in Andalusia, Spain. J Commun Health. 2020;45(4):836-45.

97. Jaeschke R, Singer J, Guyatt GH. Measurement of health status. Ascertaining the minimal clinically important difference. Control Clin Trials. 1989;10(4):407-15.

98. Cole SR, Kawachi I, Maller SJ, Berkman LF. Test of item-response bias in the CES-D scale. Experience from the New Haven EPESE study. J Clin Epidemiol. 2000;53(3):285-9.

99. Vie TL, Hufthammer KO, Holmen TL, Meland E, Breidablik HJ. Is self-rated health in adolescence a predictor of prescribed medication in adulthood? Findings from the Nord Trondelag health study and the Norwegian prescription database. SSM Popul Health. 2018;4:144-52.

100. Benjamins MR, Hummer RA, Eberstein IW, Nam CB. Self-reported health and adult mortality risk: an analysis of cause-specific mortality. Soc Sci Med. 2004:59(6):1297-306.

101. Ware JE Jr, Sherbourne CD. The MOS 36-item short-form health survey (SF-36) I Conceptual framework and item selection. Med Care. 1992;30(6):473-83.

102. Hartling L, Featherstone R, Nuspl M, Shave K, Dryden DM, Vandermeer B. Grey literature in systematic reviews: a cross-sectional study of the contribution of non-English reports, unpublished studies and dissertations to the results of meta-analyses in child-relevant reviews. BMC Med Res Methodol. 2017:17(1):64.

103. Bellefontaine SP, Lee CM. Between black and White: examining Grey literature in meta-analyses of psychological research. J Child Fam Stud. 2013;23(8):1378-88.

\section{Publisher's Note}

Springer Nature remains neutral with regard to jurisdictional claims in published maps and institutional affiliations.

Ready to submit your research? Choose BMC and benefit from:

- fast, convenient online submission

- thorough peer review by experienced researchers in your field

- rapid publication on acceptance

- support for research data, including large and complex data types

- gold Open Access which fosters wider collaboration and increased citations

- maximum visibility for your research: over $100 \mathrm{M}$ website views per year

At BMC, research is always in progress.

Learn more biomedcentral.com/submissions 